\title{
Insulin-like Growth Factor I Mediates Selective Anabolic Effects of Parathyroid Hormone in Bone Cultures
}

\author{
Ernesto Canalis, Michael Centrella, Warner Burch, and Thomas L. McCarthy \\ Department of Medicine (Endocrine Section) and Research Laboratory, Saint Francis Hospital and Medical Center, \\ Hartford, Connecticut 06105; The University of Connecticut Health Center, Farmington, Connecticut 06032; \\ and Duke University Medical Center, Durham, North Carolina 27710
}

\begin{abstract}
PTH was studied for its effects on bone formation in cultured rat calvariae. 0.01-10 $\mathrm{nM}$ PTH stimulated $\left[{ }^{3} \mathrm{H}\right]$ thymidine incorporation into DNA by up to 4.8 -fold. Although continuous treatment with PTH for 24-72 h inhibited [ ${ }^{3} \mathrm{H}$ ]proline incorporation into collagen, transient $(24 \mathrm{~h})$ treatment enhanced $\left[{ }^{3} \mathrm{H}\right]$ proline incorporation into collagen $24-48 \mathrm{~h}$ after the hormone was removed. The collagen stimulated by PTH was type $I$ and the effect was observed in the periosteum-free bone and was not blocked by hydroxyurea. Furthermore, treatment with 1-100 nM PTH for $24 \mathrm{~h}$ increased insulin-like growth factor (IGF) I concentrations by two to fourfold, and an IGF I antibody prevented the PTH stimulation of collagen synthesis, but not its mitogenic effect. In conclusion, continuous treatment with PTH inhibits calvarial collagen, whereas transient treatment stimulates collagen synthesis, and the stimulatory effect is mediated by local production of IGF I.
\end{abstract}

\section{Introduction}

Although the regulatory actions of PTH on bone resorption and mineral metabolism are well established, its effects on bone formation are complex and not well characterized (1-3). PTH stimulates bone cell replication in vitro, but continuous exposure to PTH results in decreased collagen synthesis in cultured calvariae $(4,5)$. In contrast, in vivo studies have shown that PTH increases bone formation $(6,7)$. This anabolic effect of PTH seems to be observed mostly after its administration at low or intermittent doses, suggesting that high or continuous doses of PTH cause additional or different effects on bone formation, possibly related to its catabolic actions (6, 8, 9).

Because the present therapy for osteoporosis is unsatisfactory, there have been clinical trials using PTH for the treatment of this disease. Clinical studies indicate that by increasing initial absorption of calcium and by stimulating new bone formation, PTH can restore spinal bone in patients with osteoporosis (7). However, the discrepancy between the anabolic and inhibitory effects of PTH have not been resolved and the mechanism of the anabolic response is not understood.

Address reprint requests to Dr. Ernesto Canalis, Saint Francis Hospital and Medical Center, 114 Woodland Street, Hartford, CT 06105.

Received for publication 22 July 1988 and in revised form 2 September 1988.

J. Clin. Invest.

(C) The American Society for Clinical Investigation, Inc.

0021-9738/89/01/0060/06 $\$ 2.00$

Volume 83, January 1989, 60-65
The skeletal tissue is a rich source of growth factors and bone cells have been shown to synthesize insulin-like growth factor (IGF) ${ }^{1}$ I, a known stimulator of bone cell replication and matrix synthesis (10-13). Because PTH was recently shown to stimulate the synthesis of IGF I in rat osteoblastenriched cells, it is possible that IGF I mediates the anabolic effects of PTH on the skeletal tissue (14).

These studies were undertaken to characterize the stimulatory and inhibitory actions of PTH on bone formation. For this purpose, we assessed the direct effect of PTH on bone DNA, collagen, and noncollagen protein synthesis in rat calvarial cultures and attempted to determine whether any of these effects were mediated by the local production of skeletal IGF I.

\section{Methods}

\section{Culture model}

The culture system used was previously described in detail (13). Briefly, one or two half calvariae from 21-d fetal rats were cultured in sterile 25-ml flasks containing $2 \mathrm{ml}$ of Biggers Gwatkin medium as modified by Fitton Jackson (BGJ) supplemented with $1 \mathrm{mM}$ unlabeled proline, $0.1 \mathrm{mM}$ thymidine, and heat-inactivated $\left(60^{\circ} \mathrm{C} / 2 \mathrm{~h}\right) \mathrm{BSA}(4$ $\mathrm{mg} / \mathrm{ml}$; Armour Pharmaceutical Co; Kankakee, IL), but no serum. To study effects on IGF I concentrations, calvariae were cultured in the absence of albumin or serum. The flasks were gassed with $5 \% \mathrm{CO}_{2}$ in air, sealed, and placed in a continuously shaking water bath at $37^{\circ} \mathrm{C}$ for a 24-h pre-culture period. Calvariae were then cultured in control or test medium for an additional 24-72-h period. Rat synthetic 1-34 PTH (Calbiochem-Behring Corp., La Jolla, CA) and hydroxyurea (Sigma Chemical Co., St. Louis, MO) were added directly to BGJ medium. A neutralizing-monoclonal $\kappa$ IgG antibody to human IGF I, which had some cross-reactivity with IGF II, and was kindly provided by J. J. Van Wyk (University of North Carolina, Chapel Hill, NC) (15), and a monoclonal $\kappa$ IgG antibody against a thymocyte surface antigen (T-8) generated under the same conditions and kindly provided by $B$. Haynes (Duke University, Durham, NC) were tested at a 1:1,000 dilution and added directly to BGJ medium. At this dilution the IGF I antibody has been shown to be neutralizing (15) in other systems and to block the effect of added IGF I (10 nM) on calvarial DNA and collagen synthesis (data not shown).

\section{DNA synthesis}

DNA synthesis was studied by examining effects on $\left[{ }^{3} \mathrm{H}\right]$ thymidine incorporation into DNA. [methyl $-{ }^{3} \mathrm{H}$ ] Thymidine $(5 \mu \mathrm{Ci} / \mathrm{ml}$; specific activity $60-80 \mathrm{Ci} / \mathrm{mmol}$; New England Nuclear, Boston, MA) was added during the last $60 \mathrm{~min}$ of the culture period. Calvariae were washed with cold 5\% TCA, acetone, and ether; the bones were then dried and weighed and the incorporated radioactivity was determined

1. Abbreviations used in this paper: BJG, Biggers Gwatkin medium modified by Fitton Jackson; CDP, collagenase-digestible protein; IGF, insulin-like growth factor; NCP, noncollagen protein. 
after digesting them with NCS tissue solubilizer (Amersham Corp., Arlington Heights, IL). Data are expressed as disintegrations per minute per microgram dry weight or as percent of control after dry weight correction.

\section{Histology and mitotic index}

To study effects on cell mitosis, calvariae were cultured and $N$-deacetyl- $N$-methylcolchicine (Colcemid, $4 \times 10^{-6} \mathrm{M}$; Gibco Laboratories, Grand Island, NY) was added for the last $3 \mathrm{~h}$ of the culture period. Calvariae were fixed in neutral formalin, embedded in paraffin, stained with hematoxylin-eosin and sections examined at a magnification of 250-400. Metaphase-arrested cells were counted in at least two random cross-sections taken from control or treated bone explants. Data are expressed as number of mitoses/section of half calvaria.

\section{Collagen and noncollagen protein synthesis}

Effects on newly synthesized collagen were determined by studying the incorporation of $\left[2,3-{ }^{3} \mathrm{H}\right]$ proline (specific activity $25-40 \mathrm{Ci} / \mathrm{mmol}$; New England Nuclear) into total collagen and into type I collagen. Labeled proline $(5 \mu \mathrm{Ci} / \mathrm{ml}$ for total and $50 \mu \mathrm{Ci} / \mathrm{ml}$ for type I collagen experiments) was added for the last $2 \mathrm{~h}$ of the culture period.

(a) Total collagen synthesis. Calvariae were extracted as described for DNA labeling and homogenized in $0.5 \mathrm{M}$ acetic acid. An aliquot was incubated with repurified bacterial collagenase (CooperBiomedical, Inc., Malvern, PA) and the labeled proline was incorporated into collagenase-digestible protein (CDP) and noncollagen protein (NCP) was measured according to the method of Peterkofsky and Diegelmann (16). Data are expressed as disintegrations per minute per microgram dry weight or as percent of control after dry weight correction. Percent collagen synthesis was calculated after multiplying NCP by 5.4 to correct for the relative abundance of proline in collagen and noncollagen protein (17).

(b) Type I collagen synthesis. Calvariae were rinsed with saline $(9$ $\mathrm{g} /$ liter $\mathrm{NaCl}$ ), homogenized as a pool in $0.5 \mathrm{M}$ acetic acid, digested with $1 \mathrm{mg} / \mathrm{ml}$ pepsin (Sigma Chemical Co.) over a $12-16 \mathrm{~h}$ period at $4^{\circ} \mathrm{C}$ and neutralized with sodium hydroxide. An aliquot representing one half calvaria and a radioactive type I collagen standard was dissolved in sample buffer and the collagen chains were separated on a $6 \%$ polyacrylamide gel, according to a modification of the method described by Sykes et al. (18). 2-Mercaptoethanol was applied to half of the samples $60 \mathrm{~min}$ after the electrophoresis was started (reduced collagen), whereas the other half was not treated (unreduced collagen). At the completion of the electrophoresis, the gels were fixed and the protein profiles were displayed by fluorography.

\section{Effects on periosteum and periosteum-free calvaria}

These experiments were performed to compare effects on periosteal tissue, rich in fibroblasts and osteoprogenitor cells, with those on the central calvaria which is rich in osteoblasts $(19,20)$. Intact bones were cultured and $\left[{ }^{3} \mathrm{H}\right]$ thymidine or $\left[{ }^{3} \mathrm{H}\right]$ proline was added for the last 60 or $120 \mathrm{~min}$ of the incubation period, respectively. Calvariae were washed with saline and the periosteum was removed from the superior and inferior surfaces of the bone with a scalpel blade. The incorporation of $\left[{ }^{3} \mathrm{H}\right]$ thymidine into DNA and of $\left[{ }^{3} \mathrm{H}\right]$ proline into CDP and NCP were independently determined in the periosteum and in the central bone or periosteum-free calvaria. Data are expressed as desintegrations per minute/half calvaria.

\section{IGF I assay}

IGF I concentrations were measured in the incubation medium after the 24-h pre-culture period to eliminate exogenous IGF I of maternal or fetal origin (11). IGF I was separated from its binding protein(s) by acidification ( $1 \mathrm{M}$ acetic acid final concentration) followed by size-exclusion ultrafiltration using a 10,000 -mol wt cut-off filtration device (UFP 1 LGC; Millipore Corp., Bedford, MA). Using this procedure, recovery of added IGF I was $80-100 \%$. IGF I, freed from its binding protein, was quantitated by RIA using a rabbit polyclonal antibody to human IGF I prepared by L. Underwood and J. J. Van Wyk and distributed by the National Hormone and Pituitary Program (Baltimore, MD), and a rat IGF I standard that was purified in our laboratory as previously described (11). The rabbit antiserum has $0.5 \%$ cross-reactivity with IGF II and cross-reacts minimally with insulin. Data are expressed as nanograms per milliliter of IGF I, and as nanomolar concentrations.

Statistical methods. Data are expressed as mean and SEM. Statistical differences were analyzed using $t$ test.

\section{Results}

\section{DNA synthesis and cell replication}

PTH caused a dose-related stimulation on $\left[{ }^{3} \mathrm{H}\right]$ thymidine incorporation into acid-precipitable material (DNA) in calvariae treated for $24 \mathrm{~h}$ (Fig. 1). The effect was observed at concentrations as low as $0.01 \mathrm{nM}$, and at $10 \mathrm{nM}$ PTH increased DNA labeling by 4.8 -fold. Treatment with PTH at $1 \mathrm{nM}$ for $24 \mathrm{~h}$ increased the number of metaphase-arrested cells after colcemid treatment from a control value of (mean \pm SE; $n=4$ ) $3.5 \pm 0.6$ to $6.3 \pm 0.7 \mathrm{mitoses} / \mathrm{section}(P<0.05)$, a stimulation that was observed only in the periosteal layer.

\section{Collagen and noncollagen protein synthesis}

(a) Continuous PTH treatment. Continuous treatment with PTH for a 24-h period decreased the incorporation of $\left[{ }^{3} \mathrm{H}\right]-$ proline into CDP and to a lesser extent into NCP; therefore, the percent of collagen synthesized was decreased (Fig. 2). The inhibitory effect of PTH was observed at doses as low as $1 \mathrm{pM}$, and at $0.1 \mathrm{nM}$ it decreased the labeling of CDP by $\sim 50 \%$. The inhibitory effect of PTH on the incorporation of $\left[{ }^{3} \mathrm{H}\right]$ proline into CDP was observed only after continuous exposure to the hormone and was detected for a 72-h period of treatment (Fig. 3 ). The dose response curve was similar after 24 or $72 \mathrm{~h}$ of continuous PTH treatment, and at $72 \mathrm{~h}$ PTH concentrations of $10 \mathrm{pM}$ to $10 \mathrm{nM}$ inhibited CDP labeling by $28-44 \%$ and the percent of collagen synthesized by $19-45 \%$, indicating that the inhibitory effect of PTH was more selective for collagen. In addition, the effect was observed in the presence of a concomi-

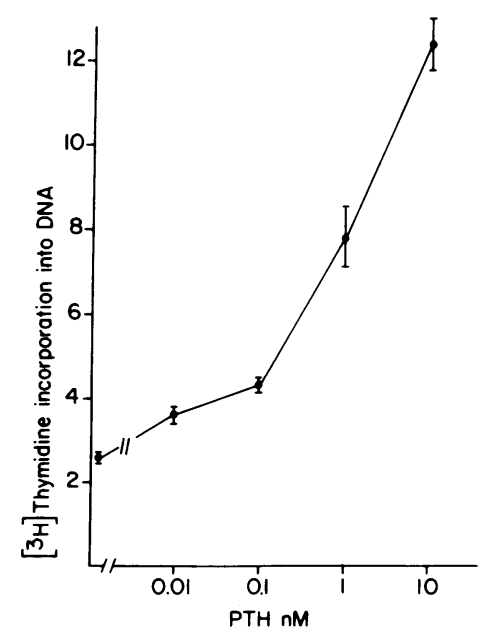

Figure 1. Effect of PTH on $\left[{ }^{3} \mathrm{H}\right]$ thymidine incorporation into acidprecipitable material (DNA) in cultured calvariae. Symbols and vertical lines represent mean values and SE for five to six half calvariae cultured for $24 \mathrm{~h}$ in the continuous presence of PTH. Data were corrected per bone dry weight (disintegrations per minute/wt). Values for all doses of PTH are significantly different from control, $P<0.05$. 

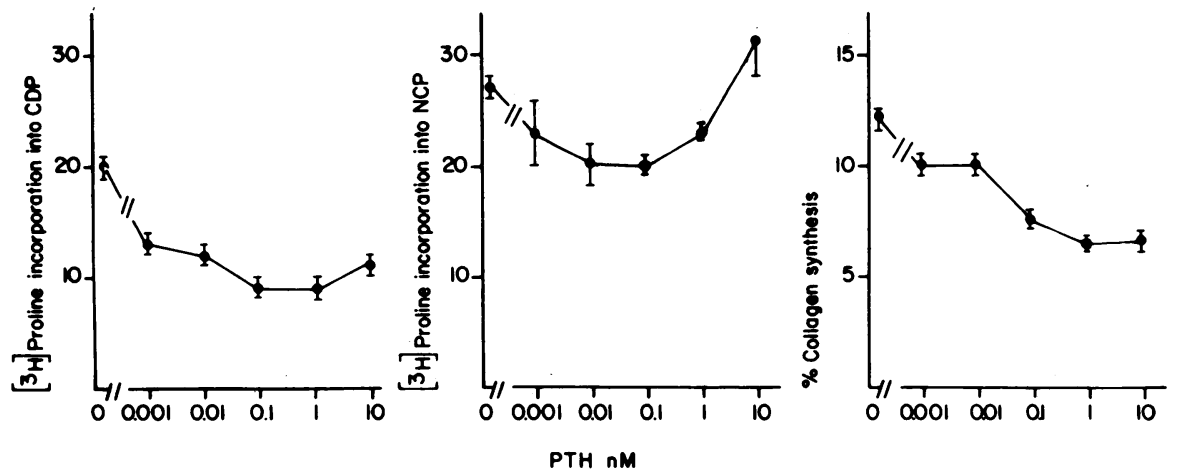

tant increase in $\left[{ }^{3} \mathrm{H}\right]$ thymidine incorporation into DNA; however, continuous exposure to PTH for 48-72 h caused a smaller stimulation of DNA synthesis than treatment for $24 \mathrm{~h}$ (Fig. 3). The stimulatory effect of PTH on DNA labeling and the inhibitory effect on collagen synthesis were not related. In a 24-h culture where $1 \mathrm{mM}$ hydroxyurea prevented the stimulatory effect of $10 \mathrm{nM}$ PTH on DNA synthesis, PTH inhibited the labeling of CDP by (mean \pm SE; $n=5$ ) $39 \% \pm 5$ in the absence $(P<0.05)$ and by $35 \% \pm 5$ in the presence of hydroxyurea $(P<0.05)$.

(b) Transient PTH treatment. In contrast to the inhibitory effect on collagen synthesis observed after continuous exposure to PTH, when calvariae were treated with PTH for $24 \mathrm{~h}$ and transferred to control (PTH-free) medium for a subsequent period of 24 or $48 \mathrm{~h}$, an increase in collagen synthesis was observed (Table I). The effect of PTH on DNA synthesis rates persisted for $24 \mathrm{~h}$ after the completion of the treatment, but disappeared $48 \mathrm{~h}$ after the removal of the hormone. Transient $(24 \mathrm{~h})$ exposure to PTH also resulted in an increase in noncollagen protein synthesis so that the effect was not specific for collagen and the percent of collagen synthesized was not changed. The stimulatory effect of PTH started to appear at doses of $0.1 \mathrm{nM}$ and at $10 \mathrm{nM}$ it increased the incorporation of $\left[{ }^{3} \mathrm{H}\right]$ proline into CDP and NCP by $70-80 \%$ (Fig. 4). Virtually all the collagen synthesized by control and treated calvariae comigrated on PAGE with a rat type I collagen standard.
Figure 2. Effect of continuous treatment with PTH on $\left[{ }^{3} \mathrm{H}\right]$ proline incorporation into $\mathrm{CDP}$ and $\mathrm{NCP}$, and on the percent of collagen synthesized in cultured calvariae. Symbols and vertical lines represent mean values and SE for 3-10 half calvariae cultured for $24 \mathrm{~h}$ in the continuous presence of PTH. Data for the labeling of CDP and $\mathrm{NCP}$ were corrected per bone dry weight (disintegrations per minute/wt) and were pooled from two experiments. All values for the effect of PTH on $\left[{ }^{3} \mathrm{H}\right]$ proline incorporation into CDP and for percent collagen synthesis and value for PTH at $0.1 \mathrm{nM}$ on $\left[{ }^{3} \mathrm{H}\right]$ proline incorporation into NCP are significantly different from control, $P<0.05$.
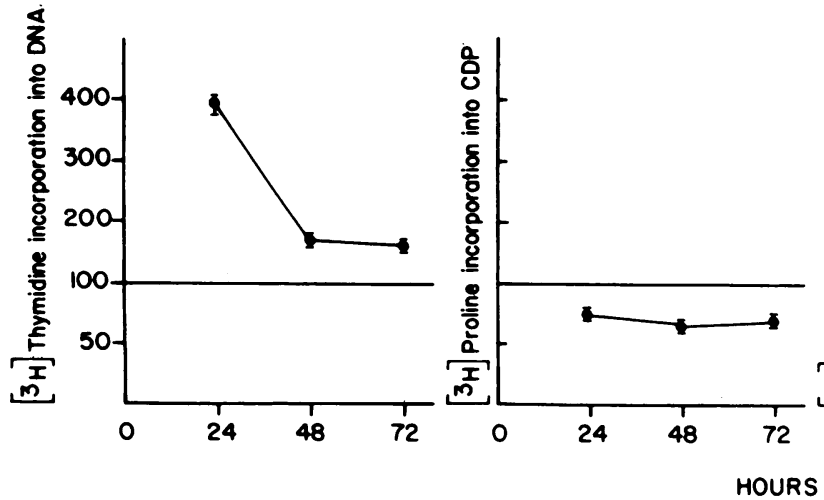

Figure 3. Effect of continuous treatment with 1 nM PTH on $\left[{ }^{3} \mathrm{H}\right]-$ thymidine incorporation into acid-precipitable material (DNA), on $\left[{ }^{3} \mathrm{H}\right]$ proline incorporation into CDP and NCP and on the percent of collagen synthesized. Calvariae were cultured in the continuous presence of PTH, for the indicated periods of time. Data for the labeling of DNA, CDP and NCP were corrected per bone dry weight (disinte-
Transient exposure to $10 \mathrm{nM}$ PTH stimulated type I collagen synthesis approximately twofold, as determined by densitometric analysis of the autoradiogram, without causing detectable changes in other collagen types (Fig. 5).

DNA synthesis rates were higher in the periosteum and collagen synthesis rates were higher in the periosteum-free, osteoblast-rich, bone of control calvariae (Table II). Treatment with PTH enhanced the incorporation of $\left[{ }^{3} \mathrm{H}\right]$ thymidine into DNA exclusively in the periosteal tissue, whereas transient exposure to the hormone enhanced the incorporation of $\left[{ }^{3} \mathrm{H}\right]-$ proline into CDP only in the periosteum-free bone. Although PTH also increased the labeling of NCP in this tissue, the effect was smaller than on CDP and the percent of collagen synthesized was enhanced after transient PTH treatment. The stimulatory effect of PTH on collagen synthesis was not a consequence of its mitogenic effect. In an experiment where PTH increased DNA synthesis by threefold ( $24 \mathrm{~h}$ after exposure to the agent) and collagen synthesis by 1.5 -fold ( $48 \mathrm{~h}$ after removal of the agent), hydroxyurea abolished the PTH effect on DNA synthesis without modifying its stimulatory effect on collagen synthesis (Table III).

\section{IGF I concentrations and neutralization experiments}

Endogenous IGF I concentrations in the culture medium of control calvariae were $10 \mathrm{ng} / \mathrm{ml}$ or $1.3 \mathrm{nM}$ and treatment with 1-100 nM PTH for $24 \mathrm{~h}$ increased IGF I levels by two to
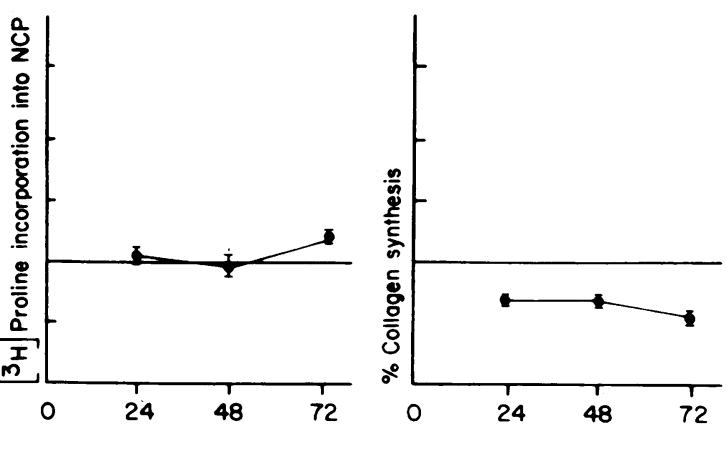

grations per minute/wt); all data are expressed as percent of control. Symbols and vertical lines represent mean values and SE for five to six half calvariae. All values for PTH, except for 24- and 48-h values for the labeling of NCP, are significantly different from control, $P<0.05$. 
Table I. Effect of Transient (24 h) PTH Treatment on DNA, Collagen, and NCP Synthesis Rates in Calvariae Cultured for 24-72 $h$

\begin{tabular}{lcccc}
\hline \multicolumn{1}{c}{ Treatment } & DNA & CDP & NCP & PCS \\
\hline & & $d p m / \mu g w t$ & & $\%$ \\
24-h culture & & & & \\
0-24 h & & & & \\
Control & $4.9 \pm 0.6$ & $25 \pm 2$ & $34 \pm 3$ & $12.1 \pm 0.5$ \\
PTH & $15.3 \pm 0.4^{*}$ & $18 \pm 2$ & $42 \pm 4$ & $7.4 \pm 0.2^{*}$ \\
48-h culture & & & & \\
0-24 h to 24-48 h & & & & \\
Control to control & $5.2 \pm 0.4$ & $22 \pm 1$ & $30 \pm 1$ & $11.9 \pm 0.5$ \\
PTH to control & $14.2 \pm 1.3^{*}$ & $31 \pm 1^{*}$ & $51 \pm 2^{*}$ & $10.2 \pm 0.2^{*}$ \\
72-h culture & & & & \\
0-24 h to 24-72 h & & & & \\
Control to control & $5.9 \pm 0.9$ & $26 \pm 1$ & $35 \pm 3$ & $12.6 \pm 0.9$ \\
PTH to control & $6.8 \pm 0.4$ & $48 \pm 3^{*}$ & $51 \pm 2^{*}$ & $15.0 \pm 0.5$ \\
& & & & \\
\hline
\end{tabular}

Values represent the 24-h effect of $10 \mathrm{nM}$ PTH, and the effect of its transient treatment on $\left[{ }^{3} \mathrm{H}\right]$ thymidine incorporation into acid-precipitable material (DNA), on $\left[{ }^{3} \mathrm{H}\right]$ proline incorporation into CDP and NCP and on the percent of collagen synthesized (PCS). Calvariae were treated only for the first $24 \mathrm{~h}$ of culture and transferred to control medium for the remainder of the incubation as indicated. Values are means $\pm S E$ for five to six half calvariae cultured for 24-72 h.

* Significantly different from control, $P<0.05$.

fourfold (Fig. 6). A neutralizing IGF I antibody did not modify the effect of PTH on $\left[{ }^{3} \mathrm{H}\right]$ thymidine incorporation into DNA. After $24 \mathrm{~h}$ of treatment, $10 \mathrm{nM}$ PTH increased DNA labeling by (mean $\pm \mathrm{SE} ; n=4-5$ ) $2.57 \pm 0.12$-fold in the absence and by $2.31 \pm 0.15$-fold in the presence of the IGF I antibody. In addition, the IGF I antibody did not alter the PTH stimulation of DNA synthesis that was observed $24 \mathrm{~h}$ after the hormone was removed (Table IV). In contrast, the IGF I antibody prevented the increase in $\left[{ }^{3} \mathrm{H}\right.$ ]proline incorporation into CDP observed after transient exposure to PTH (Table IV).

\section{Discussion}

These studies were undertaken to examine the effects of continuous and transient PTH treatment on bone formation in vitro and to determine if IGF I mediates any aspects of this process. Confirming previous observations (4), PTH caused an acute mitogenic effect because it stimulated calvarial DNA

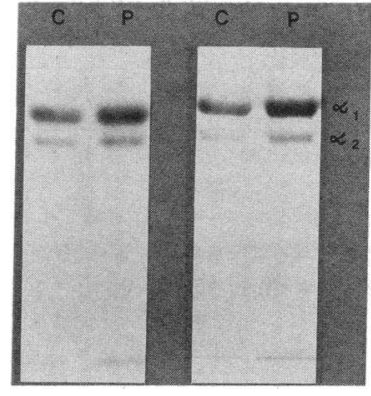

Figure 5. Polyacrylamide gel analysis of newly synthesized calvarial collagen. Calvariae were cultured in the presence of $10 \mathrm{nM}$ PTH for $24 \mathrm{~h}$ only, rinsed and transferred to control medium for an additional 48-h period and compared to control calvariae cultured for $72 \mathrm{~h}$. Newly synthesized $\alpha_{1}(\mathrm{I})$ and $\alpha_{2}$ (I) radioactive collagen chains were separated by interrupted PAGE in the absence (left) or presence (right) of 2-mercaptoethanol and were identified by comparison with a radioactive type I collagen standard. Lane $C$ represents one half control calvaria and lane $P$ one half calvaria treated with PTH.

synthesis and increased the number of colcemid-induced metaphase-arrested cells. The mitogenic effect of PTH occurred in the periosteal layer, but calvariae contain a mixed cell population and the cells affected could not be precisely identified. These cells did not appear to include differentiated osteoblasts, and osteoblast-enriched cell cultures from rat calvariae are not mitogenically responsive to PTH (21). The relevance of the mitogenic effect is not clear because neither the continuous nor the transient effect of PTH on collagen synthesis was modified in the presence of the DNA synthesis inhibitor hydroxyurea, indicating that the changes in collagen synthesis were independent of the mitogenic actions of PTH. Previous studies also have shown that the effect of PTH on bone resorption is independent of that on DNA synthesis (22). The mechanism of action of the mitogenic effect of PTH is unknown and antibody neutralization studies indicate that IGF I does not appear to mediate this effect. It is possible that other local regulators of bone remodeling, such as transforming growth factor $\beta$ (TGF $\beta$ ), are mechanistically relevant to the mitogenic actions of PTH because TGF $\beta$ is a potent mitogen for bone cells and PTH regulates the binding of TGF $\beta$ to its receptor $(21,23,24)$.

Continuous treatment with PTH for 24-72 h resulted in an inhibition of bone collagen synthesis, and this observation is in agreement with previous reports (5). In contrast, transient treatment with PTH resulted in an increase in bone collagen synthesis. The collagen synthesized was type I and the effect was observed in the periosteal-free bone, suggesting that PTH stimulated osteoblast collagen synthesis. This effect was not related to the mitogenic actions of PTH, as it was not modified by hydroxyurea, and it is possible that PTH acted on differentiated osteoblasts or on the differentiation of preosteoblastic
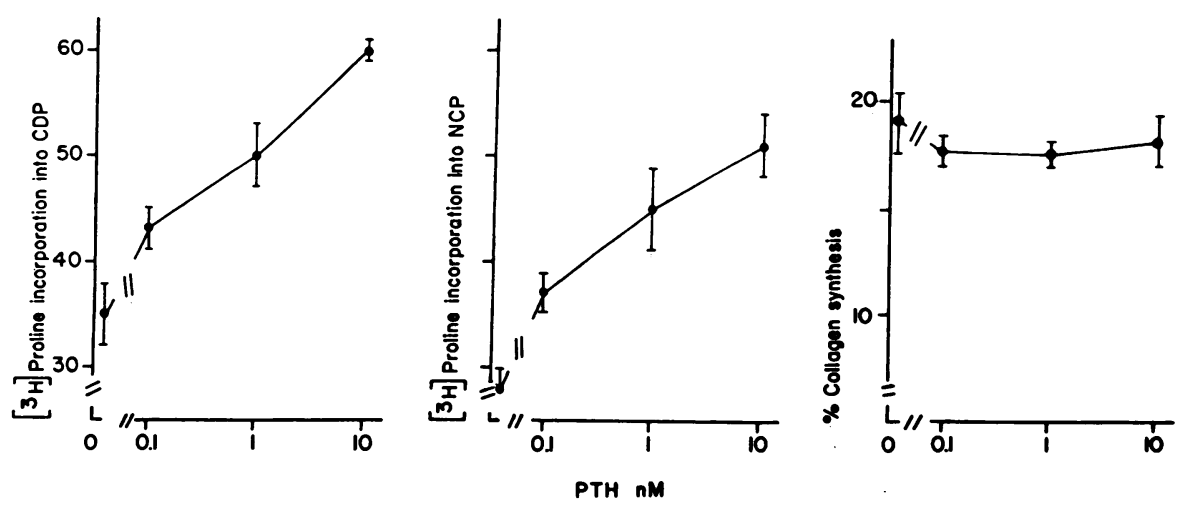

Figure 4. Effect of transient $(24 \mathrm{~h})$ treatment with PTH on $\left[{ }^{3} \mathrm{H}\right]$ proline incorporation into CDP and NCP and on the percent of collagen synthesized. Calvariae were cultured in the presence of PTH for $24 \mathrm{~h}$ only, rinsed and transferred to control medium for an additional 48-h period, and compared with control calvariae cultured for $72 \mathrm{~h}$. Data were corrected per bone dry weight (disintegrations per minute/wt). Symbols and vertical lines represent mean values and SE for six half calvariae. Values for PTH at $1-10 \mathrm{nM}$ for the labeling of CDP and at 0.1-10 $\mathrm{nM}$ for the labeling of NCP are significantly different from control, $P<0.05$. 
Table II. Stimulatory Effect of PTH on DNA, Collagen, and NCP Synthesis Rates in Periosteum and Periosteum-Free Calvaria

\begin{tabular}{ccccc}
\hline Treatment & DNA & CDP & NCP & PCS \\
\hline \multicolumn{5}{c}{ dpm/bone } \\
Periosteum \\
$\quad$ Control & $1,100 \pm 160$ & $1,790 \pm 250$ & $4,680 \pm 640$ & $6.6 \pm 0.4$ \\
$\begin{array}{l}\text { PTH } \\
\text { Periosteum-free } \\
\quad \text { calvaria }\end{array}$ & $2,730 \pm 260^{*}$ & $2,460 \pm 300$ & $6,900 \pm 790^{*}$ & $6.2 \pm 0.3$ \\
$\begin{array}{l}\text { Control } \\
\text { PTH }\end{array}$ & $650 \pm 100$ & $3,300 \pm 420$ & $2,970 \pm 230$ & $16.6 \pm 0.7$ \\
& $790 \pm 90$ & $6,530 \pm 820^{*}$ & $4,510 \pm 460^{*}$ & $20.8 \pm 1.1^{*}$ \\
\hline
\end{tabular}

Values represent the effect of $1 \mathrm{nM}$ PTH, on $\left[{ }^{3} \mathrm{H}\right]$ thymidine incorporation into acid-precipitable material (DNA) in calvariae cultured and treated for $24 \mathrm{~h}$, and the effect of $10 \mathrm{nM}$ PTH on $\left[{ }^{3} \mathrm{H}\right]$ proline incorporation into CDP and NCP and on the percent of collagen synthesized (PCS) in calvariae treated only for the first $24 \mathrm{~h}$ of a $72-\mathrm{h}$ culture. The periosteum was removed by dissection after the incubation was completed. Values are means \pm SE for 6-10 half calvariae.

* Significantly different from control, $P<0.05$.

cells. As PTH also increased noncollagen protein synthesis and calvariae contain a mixed cell population, it is possible that PTH also affected cells other than those of the osteoblastic lineage.

The results observed with PTH are similar to those observed with IGF I, which is known to stimulate osteoblast-collagen synthesis and matrix apposition rates independent of its mitogenic actions (13). It is reasonable to believe that the stimulatory effect of PTH on bone collagen synthesis is mediated by IGF I because the two agents have similar effects, PTH stimulates IGF I synthesis, and IGF I-neutralizing antibodies prevent the enhancement of calvarial collagen synthesis by PTH. Since the IGF I-neutralizing antibody cross-reacts to some extent with IGF II (15), it is conceivable that the collagen

Table III. Stimulatory Effect of PTH, in the Presence and Absence of Hydroxyurea, on Collagen and NCP Synthesis Rates in Cultured Calvariae

\begin{tabular}{cccc}
\hline Treatment $^{*}$ & CDP & NCP & PCS \\
\hline & dpm $/ \mu g w t$ & $\%$
\end{tabular}

0-24 h to 24-72 h

Control to control

PTH to control

HU to control

HU+PTH to control

$\begin{array}{ll}20 \pm 2 & 24 \pm 2 \\ 30 \pm 3^{\ddagger} & 39 \pm 3^{\ddagger} \\ 17 \pm 1 & 24 \pm 1 \\ 30 \pm 2^{\ddagger} & 36 \pm 2^{\ddagger}\end{array}$

$13.6 \pm 1.1$

$12.8 \pm 0.4$

$11.6 \pm 0.6$

$13.7 \pm 0.6$

Values represent the $(24 \mathrm{~h})$ effect of $10 \mathrm{nM}$ PTH, with and without 1 $\mathrm{mM}$ hydroxyurea $(\mathrm{HU})$ on $\left[{ }^{3} \mathrm{H}\right]$ proline incorporation into CDP and NCP and on the percent of collagen synthesized (PCS). Calvariae were treated for $24 \mathrm{~h}$ and transferred to control medium for the remainder of the incubation as indicated. Values are means $\pm S E$ for 5-12 half calvariae and were obtained by pooling two experiments. * Effects on DNA synthesis were measured at the end of the first 24 $h$ of culture and PTH increased $\left[{ }^{3} \mathrm{H}\right]$ thymidine incorporation from a control value of (mean $\pm \mathrm{SE} ; n=5) 3.6 \pm 0.4$ to $11.0 \pm 1.7 \mathrm{dpm} / \mu \mathrm{g}$ weight $(P<0.05)$; the values for $\mathrm{HU}$ and $\mathrm{HU}+\mathrm{PTH}$ were $0.6 \pm 0.1$ and $1.0 \pm 0.1 \mathrm{dpm} / \mu \mathrm{g}$ weight, respectively.

‡ Significantly different from control, $P<0.05$.

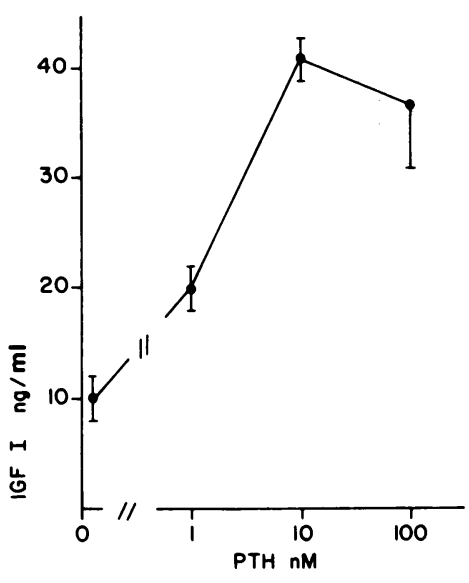

stimulatory effect of PTH could be, in part, mediated by IGF II. However, there is no current information to indicate that PTH stimulates skeletal IGF II synthesis, and IGF II acts in most systems through the IGF I receptor $(25,26)$, so that in either instance PTH would act through the same mechanism. It is likely that the local production of IGF I is important in the coupling of bone formation to bone resorption (27). PTH stimulates both bone resorption and the synthesis of IGF I, and this newly synthesized IGF I could be important in the formation of new bone.

Previous observations have indicated that IGF I mediates the effects of growth hormone on bone formation (28), and our studies confirm that local skeletal factors act as intermediaries of hormonal action because IGF I mediates the anabolic effects of PTH. Our investigations also provide an explanation for some of the previously reported discrepancies between the

Table IV. Stimulatory Effect of PTH, in the Presence and Absence of an IGF I Antibody, on DNA, Collagen, and NCP Synthesis Rates in Cultured Calvariae

\begin{tabular}{rrrrr}
\hline Treatment $^{*}$ & DNA & CDP & NCP \\
\hline & & dpm/ $\mu g w t$
\end{tabular}

0-24 h to 24-48 h (DNA)

0-24 h to 24-72 h (CDP, NCP)

BGJ medium

Control BGJ to BGJ

PTH to BGJ

Control antibody (CA)

CA to CA

$\mathrm{PTH}+\mathrm{CA}$ to CA

IGF I antibody (IGF Ab)

IGF $A b$ to IGF $A b$

PTH+IGF Ab to IGF Ab

$\begin{array}{ccc}4.0 \pm 0.2 & 35 \pm 3 & 28 \pm 2 \\ 13.0 \pm 0.9^{\ddagger} & 60 \pm 1^{\ddagger} & 51 \pm 3^{\ddagger} \\ & & \\ 5.8 \pm 1.0 & 25 \pm 2 & 31 \pm 2 \\ 12.8 \pm 1.1^{\ddagger} & 60 \pm 6^{\ddagger} & 50 \pm 6^{\ddagger} \\ & & \\ 6.9 \pm 0.6 & 33 \pm 4 & 40 \pm 3 \\ 13.3 \pm 0.4^{\ddagger} & 42 \pm 2 & 50 \pm 3^{\ddagger}\end{array}$

Values represent the effect of $10 \mathrm{nM}$ PTH, with and without an IGF I antibody (IGF Ab) or a control antibody (CA) raised to a T-8 lymphocyte surface antigen, both at a 1:1,000 dilution, on $\left[{ }^{3} \mathrm{H}\right]$ thymidine incorporation into acid-precipitable material (DNA), and on $\left[{ }^{3} \mathrm{H}\right]$ proline incorporation into CDP and NCP. Values are means \pm SE for six half calvariae.

* Calvariae were treated for $24 \mathrm{~h}$ and transferred to the indicated medium for an additional 24-h (DNA) or 48-h (CDP and NCP) period.

¥ Significantly different from respective control, $P<0.05$. 
stimulatory and inhibitory effects of PTH on bone collagen synthesis and confirm that the anabolic effect of PTH is primarily observed after intermittent treatment $(6,8,9)$. Since collagen is the major component of the bone matrix, it is reasonable to expect that changes in bone formation would parallel those on collagen synthesis. It is unclear why continuous exposure to PTH results in an inhibition of collagen synthesis despite increased IGF I concentrations, but our previous studies have shown that continuous treatment with PTH opposes the stimulatory activities of IGF I on collagen synthesis (12). It is therefore apparent that PTH overrides the IGF I-dependent stimulation, possibly by modifying specific osteoblast-differentiated functions. Although the mechanism of the inhibitory effect of PTH is not known, based upon this and previous reports $(6,8,9)$, it would seem appropriate to use intermittent instead of continuous PTH in therapeutic trials for osteoporosis.

In conclusion, continuous treatment of rat calvarial cultures with PTH results in an inhibition of collagen synthesis, whereas transient treatment stimulates collagen synthesis, and this effect appears secondary to the local production of skeletal IGF I.

\section{Acknowledgments}

The authors thank Drs. L. Underwood, J. J. Van Wyk, and B. Haynes and the National Hormone and Pituitary Program for reagents used for these studies; Miss Sandra Casinghino, Mrs. Michele Kervick, Mrs. Bari Gabbitas, and Mrs. Sheila Rydziel for expert technical assistance; and Mrs. Nancy Brignoli for valuable secretarial help.

This work was supported by grant AR-27107 from the National Institute of Arthritis and Musculoskeletal and Skin Diseases.

\section{References}

1. Raisz, L. G. 1965. Bone resorption in tissue culture. Factors influencing the response to parathyroid hormone. J. Clin. Invest. 44:103-116.

2. Parsons, J. A. 1976. Parathyroid physiology and the skeleton. In The Biochemistry and Physiology of Bone. Vol. 4. G. H. Bourne, editor. Academic Press, Inc., New York. 2nd ed. 159-225.

3. Canalis, E. 1983. The hormonal and local regulation of bone formation. Endocr. Rev. 4:62-77.

4. MacDonald, B. R., J. A. Gallagher, and R. G. G. Russell. 1986. Parathyroid hormone stimulates the proliferation of cells derived from human bone. Endocrinology. 118:2445-2449.

5. Dietrich, J. W., E. M. Canalis, D. M. Maina, and L. G. Raisz. 1976. Hormonal control of bone collagen synthesis in vitro. Effects of parathyroid hormone and calcitonin. Endocrinology. 98:943-949.

6. Tam, C. S., J. N. M. Heersche, T. M. Murray, and J. A. Parsons. 1982. Parathyroid hormone stimulates the bone apposition rate independently of its resorptive action: differential effects of intermittent and continuous administration. Endocrinology. 110:506-512.

7. Slovik, D. M., D. I. Rosenthal, S. H. Doppelt, J. T. Potts, Jr., M. A. Daly, J. A. Campbell, and R. M. Neer. 1986. Restoration of spinal bone in osteoporotic men by treatment with human parathyroid hormone (1-34) and 1,25-dihydroxyvitamin D. J. Bone Min. Res. $1: 377-381$.

8. Hock, J. M., G. J. Fonseca, and L. G. Raisz. 1988. Human parathyroid hormone-(1-34) increases bone mass in ovariectomized and orchidectomized rats. Endocrinology. 122:2899-2904.

9. Slovik, D. M., R. M. Neer, and J. T. Potts. 1981. Short-term effects of synthetic human parathyroid hormone-(1-34) administration on bone mineral metabolism in osteoporotic patients. J. Clin. Invest. 68:1261-1271.
10. Canalis, E., T. McCarthy, and M. Centrella. 1988. Growth factors and the regulation of bone remodeling. J. Clin. Invest. 81:277281.

11. Canalis, E., T. McCarthy, and M. Centrella. 1988. Isolation and characterization of insulin-like growth factor I (Somatomedin C) from cultures of fetal rat calvariae. Endocrinology. 122:22-27.

12. Canalis, E. 1980. Effect of insulin-like growth factor I on DNA and protein synthesis in cultured rat calvaria. J. Clin. Invest. 66:709719.

13. Hock, J. M., M. Centrella, and E. Canalis. 1988. Insulin-like growth factor I (IGF-I) has independent effects on bone matrix formation and cell replication. Endocrinology. 122:254-260.

14. McCarthy, T. L., M. Centrella, and E. Canalis. 1988. The transcript and polypeptide levels of insulin-like growth factor I in osteoblast-enriched parietal bone cell cultures are stimulated by parathyroid hormone. J. Bone Min. Res. 3(Suppl. 1):218a. (Abstr.)

15. Russell, W. E., J. J. Van Wyk, and W. J. Pledger. 1984. Inhibition of the mitogenic effects of plasma by a monoclonal antibody to somatomedin C. Proc. Natl. Acad. Sci. USA. 81:2389-2392.

16. Peterkofsky, B., and R. Diegelmann. 1971. Use of a mixture of proteinase-free collagenases for the specific assay of radioactive collagen in the presence of other proteins. Biochemistry. 10:988-993.

17. Peterkofsky, B. 1972. The effect of ascorbic acid on collagen polypeptide synthesis and proline hydroxylation during the growth of cultured fibroblasts. Arch. Biochem. Biophys. 152:318-328.

18. Sykes, B., B. Puddle, M. Francis, and R. Smith. 1976. The estimate of two collagens from human dermis by interrupted gel electrophoresis. Biochem. Biophys. Res. Commun. 72:1472-1480.

19. Peck, W. A., S. J. Birge, and S. A. Fedak. 1964. Bone cells: biochemical and biological studies after enzymatic isolation. Science (Wash. DC). 146:1476-1477.

20. Wong, G. L., and D. V. Cohn. 1975. Target cells in bone for parathormone and calcitonin are different. Enrichment for each cell type by sequential digestion of mouse calvaria and selective adhesion to polymeric surfaces. Proc. Natl. Acad. Sci. USA. 72:3167-3171.

21. Centrella, M., T. L. McCarthy, and E. Canalis. 1988. Parathyroid hormone modulates transforming growth factor $\beta$ activity and binding in osteoblast-enriched cell cultures from fetal rat parietal bone. Proc. Natl. Acad. Sci. USA. 85:5889-5893.

22. Lorenzo, J. A., L. G. Raisz, and J. M. Hock. 1983. DNA synthesis is not necessary for osteoclastic responses to parathyroid hormone in cultured fetal rat long bones. J. Clin. Invest. 72:19241929.

23. Centrella, M. and E. Canalis. 1985. Transforming and nontransforming growth factors are present in medium conditioned by fetal rat calvariae. Proc. Natl. Acad. Sci. USA. 82:7335-7339.

24. Centrella, M., T. L. McCarthy, and E. Canalis. 1987. Transforming growth factor Beta is a bifunctional regulator of replication and collagen synthesis in osteoblast-enriched cell cultures from fetal rat bone. J. Biol. Chem. 262:2869-2874.

25. Kiess, W., J. F. Haskell, L. Lee, L. A. Greenstein, B. E. Miller, A. L. Aarons, M. M. Rechler, and P. S. Nissley. 1987. An antibody that blocks insulin-like growth factor (IGF) binding to the type II IGF receptor is neither an agonist nor an inhibitor of IGF-stimulated biologic responses in L6 myoblasts. J. Biol. Chem. 262:12745-12751.

26. Furlanetto, R. W., J. N. DiCarlo, and C. Wisehart. 1987. The type II insulin-like growth factor receptor does not mediate deoxyribonucleic acid synthesis in human fibroblasts. J. Clin. Endocrinol. 64:1142-1149.

27. Howard, G. A., B. L. Bottemiller, R. T. Turner, J. I. Rader, and D. J. Baylink. 1981. Parathyroid hormone stimulates bone formation and resorption in organ culture: evidence for a coupling mechanism. Proc. Natl. Acad. Sci. USA. 78:3204-3208.

28. Ernst, M., and E. R. Froesch. 1988. Growth hormone dependent stimulation of osteoblast-like cells in serum-free cultures via local synthesis of insulin-like growth factor I. Biochem. Biophys. Res. Commun. 151:142-147. 